\title{
Correction to: Innovativeness and Competitiveness of Polish Service Enterprises Under the Conditions of Market Liberalization in the Central and Eastern Europe
}

Anna Dąbrowska and Adrian Lubowiecki-Vikuk

\section{Correction to:}

Chapter "Innovativeness and Competitiveness of Polish Service Enterprises Under the Conditions of Market Liberalization in the Central and Eastern Europe" in: V. Ratten (ed.), Entrepreneurship and Organizational Change, Contributions to Management Science, https://doi.org/10.1007/978-3-030-35415-2_2

The original version of the chapter was published without the grant number. The chapter and book have been updated with the changes. 